\section{Response to comments by Kersting et al.}

We welcome the response to our recent article (Reilly \& Wells, 2005), in part because we wanted to encourage the collection and publication of more empirical data on milk energy transfer from mothers who breast-feed exclusively up until their baby is 5-6 months old. Kersting et al. (2006) provide new data on the quantity of breast-milk transferred in thirtynine mother-infant pairs, collected over a 16-year period in Germany. As we and others have noted, there is a dearth of energy-balance data for mother-infant pairs exclusively breast-feeding beyond 4 months (Butte et al. 2002; Reilly et al. 2005). Kersting et al. (2006) stated that fewer than $20 \%$ of the mothers in their sample were 'exclusive and predominant breast-feeders' by 6 months, and it is likely that the small minority still breast-feeding exclusively at 6 months were atypical.

This problem of massive attrition from longitudinal studies of milk transfer in exclusive breast-feeding is serious, and we cannot have confidence that those who remain in such studies represent all other mother-infant pairs (Butte et al. 2002). Mothers who remain in such studies, including the Dortmund Nutritional and Anthropometric Longitudinally Designed Study (Kersting et al. 2006), are highly self-selected and may be particularly able to meet the energy requirements of their baby by exclusive breast-feeding. How they do so, and how typical they are, are questions that require further study. Basing population-wide recommendations for the duration of exclusive breast-feeding on the experience of a small minority of (possibly atypical) mother-infant pairs seems to us to be premature, particularly in the light of the doubts that our review of empirical data have presented.

Kersting et al. (2006) questioned whether the UK infant weight reference data we used to estimate energy requirements were largely based on formula-fed infants, who might have been heavier than exclusively breast-fed infants of the same age. The UK 1990 weight reference data in infancy (Freeman et al. 1995) were derived from several sources, notably the Cambridge Infant Growth Study (Cole et al. 2002), with a higher proportion of the sample breast-feeding than was typical of the UK at the time. Furthermore, despite differences in the patterns of growth, the weight of exclusively breast-fed infants in the Cambridge Infant Growth Study at 5-6 months was similar to that of the rest of the cohort (Cole et al. 2002).

The main scientific question, based on the accumulated body of evidence from our systematic review (Reilly et al. 2005), remains whether or not infants of average weight or above in the UK can obtain sufficient milk energy from exclusive breast-feeding at 6 months of age. Larger prospective studies of all components of the infant energy-balance equation are necessary to answer this question. Although exclusive breast-feeding provides sufficient energy for some infants at 6 months, published data suggest that, for infants of average weight or above, meeting infant energy needs will become increasingly difficult by 6 months. We support the suggestion by Kersting et al. (2006) that more energy-balance research is necessary in order to address whether (and how) the recommendation to breast-feed exclusively is achievable by more typical mother-infant pairs.

Finally, we emphasise that the issue of the adequacy of exclusive breast-feeding to 6 months merits greater attention in order to promote breast-feeding successfully in the whole population.

John J. Reilly ${ }^{1}$ and Jonathan C. K. Wells ${ }^{2}$

${ }^{1}$ University of Glasgow Division of Developmental Medicine 1st Floor Tower QMH Yorkhill Hospitals Glasgow G3 8SJ $U K$

${ }^{2}$ MRC Childhood Nutrition Research Centre Institute of Child Health University College London 30 Guilford $S t$ London WC1N 1EHUK

Email: jjr2y@clinmed.gla.ac.uk

10.1079/BJN20061769

\section{References}

Butte NF, Lopez-Alarcon MG \& Garza C (2002) Nutrient Adequacy of Exclusive Breastfeeding for the Term Infant During the First Six Months of Life. Geneva: WHO.

Cole TJ, Paul AA \& Whitehead RG (2002) Weight reference charts for British long-term breastfed infants. Acta Paediatr 91, 1296-1300.

Freeman JV, Cole TJ, Chinn S, Jones PRM, White EM \& Preece MA (1995) Cross sectional stature and weight curves for the UK, 1990. Arch Dis Child 73, 17-24.

Kersting M, Hilbig A \& Schoen S (2006) Comments by Kersting et al. Br J Nutr 95, 1229-1230.

Reilly JJ, Ashworth S \& Wells JCK (2005) Energy intake in the exclusively breast-fed infant age 3-6 months from developed countries: a systematic review. Br J Nutr 94, 56-63.

Reilly JJ \& Wells JCK (2005) Duration of exclusive breast-feeding: introduction of complementary feeding may be necessary before 6 months of age. Br J Nutr 94, 869-872. 